\title{
Identifikasi Keberadaan Air pada Proses Penyaluran Fluida Produksi di Lapangan Minyak Lepas Pantai
}

\section{Identification of The Presence of Water in The Production Fluid Distribution Process in the Offshore Oil Field}

\author{
Hariyadi $^{1 *}$, Dedy Kristanto ${ }^{2}$ dan Yulius Deddy Hermawan ${ }^{3}$ \\ ,1,2 Program Studi Teknik Perminyakan, Fakultas Teknologi Mineral, UPN ”Veteran” Yogyakarta, Jl. Padjajaran 104 \\ (Lingkar Utara), Condongcatur, Yogyakarta, Indonesia 55283 \\ ${ }^{3}$ Program Studi Teknik Kimia, Fakultas Teknik Industri, UPN ”Veteran” Yogyakarta, Jl. Padjajaran 104 (Lingkar Utara), \\ Condongcatur, Yogyakarta, Indonesia 55283
}

\section{Artikel histori : \\ Diterima 7 September 2020 Diterima dalam revisi 26 Oktober 2020 Diterima 28 Oktober 2020 Online 31 Oktober 2020}

\begin{abstract}
ABSTRAK: Produksi minyak yang mengalir dari Anjungan menuju FSO (Floating Storage and Offloading) "A" berasal dari PT. Perusahaan Minyak "B" dan "C" di Selat Madura. Total produksi minyak yang mengalir dari anjungan ke FSO "A" saat ini sekitar 6000 BOPD. Akibat sistem pengiriman yang menggunakan saluran pipa yang sama maka timbul masalah yaitu kehilangan minyak antara Platform sebagai titik pengiriman dan FSO "A" sebagai titik penerima. Selain itu, air yang ikut dalam proses distribusi minyak akan menjadi faktor pengurang yang akan digunakan sebagai koreksi pengiriman minyak, semakin banyak air semakin sedikit jumlah minyak yang akan diterima di FSO "A". Sampel minyak yang telah diambil kemudian diamati karakteristiknya yaitu densitas, komposisi (\% mole), BS\&W, emulsi, flash, dan penyusutan yang diuji di Laboratorium PPPTMGB "Lemigas" Jakarta. Berat jenis sampel sekitar 1.018, dan keduanya sangat berbeda dengan berat jenis air laut; Perbedaan ini ditunjukkan oleh hasil SG (1.018 vs 1.025) dan kadar garam air laut jauh lebih tinggi dibandingkan air formasi PT "B" dan PT "C". Sampel minyak dari PT "B" dan PT "C" memiliki SG yang hampir sama, yaitu 0.79. Kadar BS\&W pada kedua produsen minyak cukup rendah; Hal ini menunjukkan bahwa pemisahan minyak dan air di Anjungan berjalan cukup baik. Namun, sampel BS\&W di FSO "A" yang masuk sangat tinggi, yaitu lebih dari 5\%; ini menunjukkan off-set pada pengaturan level antarmuka air-minyak pada separator sehingga air dapat menambah jumlah volume aliran minyak dari Platform ke FSO "A"
\end{abstract}

Kata Kunci: Kadar air, BS\&W, produksi minyak, produksi air
ABSTRACT: Oil production that flows from the Platform to the FSO (Floating Storage and Offloading) "A" is derived from PT. "B" and the "C" Oil Company in the Madura Strait. The total oil production flowing from the Platform to the "A" FSO is currently around 6000 BOPD. As a result of the delivery system using the same channel, a problem arises, namely oil losses between the Platform as a delivery point and FSO "A" as a receiving point. Besides that, the water that is involved in the oil distribution process will be a deduction factor that will be used as a correction for oil shipments, the more water the less amount of oil will be received at FSO "A". The oil samples that have been taken are then observed for their characteristics, namely density, composition (\%-mole), BS\&W, emulsion, flash, shrinkage at PPPTMGB "Lemigas" Laboratory Jakarta. The specific gravity of samples is around 1,018. While the characteristics of the two are different from the characteristics of sea water; this difference is shown by the results of SG $(1,018$ vs 1,025$)$ and the salt content of sea water is much higher than the water formation of PT "B" and PT "C". The oil samples of PT "B" and PT "C" have almost the same SG, which is 0.79 . BS\&W oil in both ships is quite low; this shows that the separation of oil and water on the Platform went quite well. However, BS\&W samples in incoming FSO "A" are very high, at $5 \%$; this indicates an off-set at the water-oil interface level settling time on the Platform separator so that water can be joined with the oil flow from the Platform to the FSO "A"

Keywords: Water content, BS\&W, oil production, water production 


\section{Pendahuluan}

Pada system custody transfer, minyak bumi yang diproduksi dari lapangan dikumpulkan pada beberapa stasiun pengumpul, untuk kasus di lepas pantai stasiun pengumpul berupa FSO, kemudian dikapalkan atau diserahkan menuju suatu terminal penyimpanan akhir, siap untuk dijual atau diserahkan ke tempat lain.

Pengalaman lapangan menunjukkan bahwa, ketika dua atau lebih minyak bumi yang memiliki perbedaan karakteristik bertemu dan ditransportasikan melalui pipa secara bersamaan, campuran tersebut akan membentuk suatu minyak bumi yang mempunyai karekteristik yang berbeda daripada minyak bumi aslinya. Disamping itu, jumlah total minyak bumi yang diserahkan dari stasiun pengumpul, sebagai titik serah, akan berbeda dari pada jumlah total minyak bumi yang diterima pada tangki terima. Perbedaan jumlah pengiriman dan penerimaan ini disebut oil losses. Jumlah yang diterima di terminal penyimpanan akhir lebih rendah daripada jumlah total yang diserahkan dari beberapa titik serah. Oil losses dapat disebabkan oleh beberapa faktor, antara lain:

a. Penyusutan (shrinkage) volume minyak bumi yang disebabkan proses pencampuran dua atau lebih minyak bumi yang memiliki perbedaan karakteristik dalam pipa atau tanki.

b. Kehilangan minyak bumi karena emulsi minyak dan air yang stabil.

c. Penguapan minyak bumi dalam tangki selama penyimpanan disebabkan pemanasan oleh kondisi sekitar.

d. Kesalahan dalam pengukuran yang dapat terjadi pada pengukuran volume minyak yang keluar dari tangki serah atau masuk ke tangki pengumpul/penyimpanan dan pada penetapan Specific Gravity, SG, dan Basic Sediment \& Water, BS\&W, yang menyebabkan kesalahan pada perhitungan faktor koreksi volume. Kesalahan pengukuran dapat terjadi karena deviasi kalibrasi peralatan pengukuran. (Intertanko, 1996)

e. Kebocoran pada sistem pemipaan menyebabkan kehilangan minyak bumi.

Tingginya kadar air dalam pengiriman akan menyebabkan berkurangnya volume minyak yang diterima di stasiun penerimaan, akan menjadi masalah tersendiri bila pihak pengirim merasa yakin sudah mengirimkan minyak dengan kadar air yang ditetapkan tetapi terjadi kenaikan kadar air di tangki atau stasiun penerimaan.hal inilah yang dialami oleh PT "B" dan PT "C" yang mengirimkan mininyak FSO "A", dimana terjadi kenaikan air di FSO "A" padahal kedua belah pihak yakin sudah mengirimkan minyak sesuai standar, tetapi di FSO "A" ditemukan air yang berlebihan.

\section{Metode Penelitian}

Ada dua shipper penghasil minyak jalur PT "B" dan PT "C" ke FSO "A". Konfigurasi transportasi minyak bumi jalur tersebut melibatkan 2 (dua) pencampuran minyak bumi pada sistem jaringan transportasi pemipaan. Kondisi ini sudah barang tentu akan menyebabkan terjadi shrinkage akibat pencampuran dua minyak bumi, yang dapat mengarah pada terjadinya oil losses, dalam perhitungan ini juga akan di hitung seberapa besar losses yang disebabkan adanya emulsi dalam sistem minyak, hal ini juga akan menjadi sumber keberadaan air bila terdapat emulsi air yang tinggi didalam sistem minyak. (Jones P, 1985) Untuk itu diperlukan metoda analisa di laboratorium meliputi:

a. Survei, pengumpulan data dan sampling minyak bumi di 4 titik sampling.

b. Pengukuran komposisi hydrocarbon dalam minyak bumi (\% mol)

c. Pengukuran sifat fisik dan kimia minyak bumi, yaitu SG 60/60, BS\&W, free water, densitas, distillasi hempel, gas chromatography dan blending.

d. Pengukuran sifat fisik air formasi dan air laut: SG60/60 dan salt content.

e. Evaluasi data laboratorium, untuk menetapkan faktor koreksi (faktor shrinkage dan faktor emulsi)

f. Evaluasi air formasi dan air laut

Kegiatan penelaahan utama yang dilaksanakan pada pekerjaan ini adalah :

a. Melakukan uji laboratorium atas sampel yang diperoleh berdasarkan sampling di lapangan dan evaluasi hasil uji laboratorium;

b. Melakukan perhitungan penentuan faktor koreksi produksi terhadap minyak dari kedua shipper.

Data yang diperoleh dianalisis dengan cara pendekatan kuantitatif. Pendekatan kuantitatif meliputi analisis dan evaluasi terhadap penyusutan (shrinkage), kemungkinan terjadinya emulsi stabil dan penguapan berdasarkan hasil uji dan percobaan di Laboratorium PPPTMGB "LEMIGAS" Jakarta. Strategi tahapan kegiatan yang dilakukan untuk mencapai sasaran studi hasil analisa laboratorium ditunjukkan pada Gambar 1.

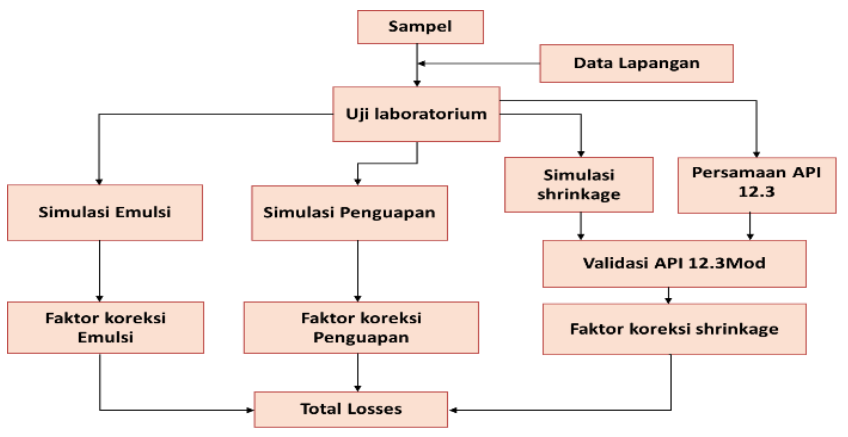

Gambar 1. Diagram Alir Tahapan Kegiatan Laboratorium Pada Penentuan Losses

\section{Perhitungan Emulsi Minyak}

Seperti diketahui, dalam minyak bumi yang diproduksi dari sumur minyak bumi, juga terikut air formasi. Sebelum dikirim ke Pusat Pengumpul Produksi (PPP) atau Floating Storage Off-loading (FSO), air formasi yang terikut dipisahkan terlebih dahulu melalui pendiaman dalam tangki 
lapangan (settling time). Namun demikian, masih terdapat kandungan air dalam minyak bumi yang dikirim dalam bentuk emulsi meskipun dalam jumlah sedikit. Kandungan air dan sedimen yang sedikit tersebut dapat mempengaruhi langsung perhitungan volume minyak bumi. Oleh karena itu, dalam kajian ini pengaruh emulsi air dalam minyak terhadap oil losses perlu dikaji dan diuji, yang garis besar metodologinya adalah sebagai berikut:

a. Minyak bumi dicampur dengan air formasinya pada beberapa tingkat penambahan volume air dan diamati perubahan SG dan BS\&W-nya

b. Perubahan SG dan BS\&W tersebut digambarkan dalam suatu kurva yang akan menghasilkan suatu persamaan pertama $Y_{l}=a_{1} X_{l}+b_{1}$

c. Kemudian dibuat kurva SG dan $\%$ penambahan air formasi dimana $\mathrm{SG}$ dioperoleh berdasarkan perhitungan, kurva tersebut akan memberikan persamaan kedua $Y_{2}=a_{2} X_{2}+b_{2}$. Nilai SG perhitungan tersebut diperoleh menggunakan formula dibawah ini:

$$
\mathrm{SG}_{\text {calculated }}=\left(1-\mathrm{X}_{\mathrm{W}}\right) \mathrm{SG}_{\mathrm{fw}}+\mathrm{X}_{\mathrm{w}} \mathrm{SG}_{\mathrm{w}}
$$

dimana $X_{w}$ adalah fraksi air dalam minyak, $\mathrm{SG}_{\mathrm{w}}$ adalah specific gravity air formasi, dan $\mathrm{SG}_{\mathrm{fw}}$ adalah specific gravity minyak bebas air yang dirumuskan berikut:

$$
S G_{f w}=\frac{S G_{o}-X_{w} S G_{w}}{\left(1-X_{w}\right)}
$$

dimana $\mathrm{SG}_{\mathrm{o}}$ is specific gravity minyak yang masih mengandung air. Kedua persamaan tersebut dikorelasikan dengan memasukkan data BS\&W awal dari minyak yang diuji sebagai $X_{1}$ sehingga diperoleh nilai $Y_{1}$, yang kemudian $Y_{1}$ tersebut disubstitusikan ke persamaan kedua sehingga diperoleh nilai $X_{2}$.

d. Faktor koreksi emulsi $=$ selisih BS\&W dari kurva perhitungan dan kurva aktual

e. Faktor koreksi yang diakibatkan oleh emulsi diperoleh dari $X_{1}-X_{2}$.

Sebagai ilustrasi kedua grafik tersebut adalah seperti yang disajikan dalam Gambar 2.

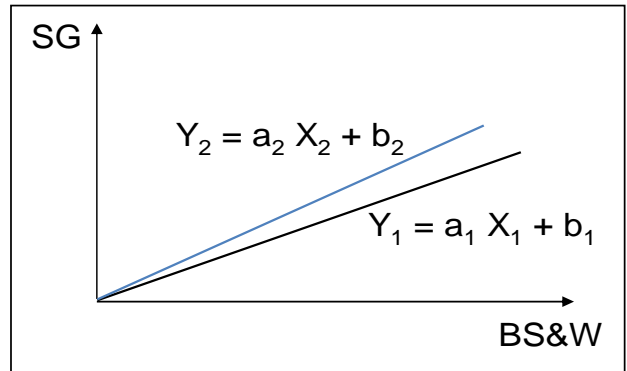

Gambar 2. Grafik Perubahan SG terhadap BS\&W Percobaan Laboratorium dan Perhitungan

\section{Metode Pengujian Laboratorium}

Dalam kajian oil losses ini dilakukan pengambilan sampel dan pengujian laboratorium terutama sifat fisika yang berkaitan dengan penghitungan volume minyak bumi yang diserahkan dan penyebab terjadinya oil losses. Pengujian laboratorium terhadap sampel minyak bumi dilakukan seperti yang tercantum dalam Tabel 1 .

(API MPMS Chapter 10.2) dan (Analisa BS \& W By Centrifuge ASTM - D - 6/API-2542)

Tabel 1. Mata Uji dan Metode

\begin{tabular}{cll}
\hline No & \multicolumn{1}{c}{ Mata Uji } & \multicolumn{1}{c}{ Metode } \\
\hline 1 & $\begin{array}{l}\text { Analisis Kandungan Air Sedimen } \\
\text { (BS\&W) dengan cara Pemusingan }\end{array}$ & ASTMD-4007 \\
2 & Pengukuran Spesific Gravity & ASTMD-1298 \\
3 & Pengukuran Densitas & ASTMD-5002 \\
4 & Distilasi Sampel & ASTMD-285 \\
& & modified \\
5 & Free Water & $\begin{array}{l}\text { ASTMD-2892 } \\
\text { (Dehidrasi) }\end{array}$ \\
\hline
\end{tabular}

Lokasi Pengambilan Sampel

Pengambilan sampel untuk pengujian laboratorium dilakukan di lapangan pada 4 titik sampel yang terdiri atas 4 sampel minyak bumi beserta air formasinya. Sampel yang diambil dan lokasi pengambilan sampel adalah seperti tercantum pada Tabel 2 .

Tabel 2. Lokasi Pengambilan Sampel

\begin{tabular}{cccccc}
\hline No & $\begin{array}{c}\text { Sampling } \\
\text { Point }\end{array}$ & Tipe & $\begin{array}{c}\text { Jumlah } \\
\text { jerry can } \\
\text { (20L) }\end{array}$ & $\begin{array}{c}\text { Air } \\
\text { Formasi } \\
\text { (Botol } \\
\text { 2L) }\end{array}$ & $\begin{array}{c}\text { Botol } \\
\text { GC }\end{array}$ \\
\hline 1 & $\begin{array}{l}\text { Separator V- } \\
103 \text { (PT "B") } \\
2\end{array}$ & Oil & 1 & 1 & 1 \\
\hline $\begin{array}{l}\text { Separator V- } \\
603 \text { (PT "C") }\end{array}$ & Oil & 1 & 1 & 1 \\
\hline $\begin{array}{l}\text { Incoming } \\
\text { FSO "A" } \\
\text { Tangki 3C } \\
\text { FSO "A" }\end{array}$ & Oil & 1 & 1 & 1 \\
\hline
\end{tabular}

Selain itu, sampel air laut juga diambil sebagai tambahan data untuk mendukung keberadaan air jalur minyak ke FSO "A", hal ini dilakukan untuk membuktikan ada tidaknya intrusi air laut kedalam pipa penyaluran minyak.

\section{Hasil dan Pembahasan}

Dari hasil kunjungan ke lapangan yang dilakukan untuk kedua produsen minyak didapatkan hasil produksi minyak bumi masing-masing lapangan dicantumkan di dalam Tabel 3, sedangkan pada Tabel 4 menyajikan data survei dan sampling pendahuluan yang dilakukan pada tanggal observasi lapangan

Tabel 3. Jumlah Produksi Minyak (rata-rata tanggal obeservasi lapangan)

\begin{tabular}{llc}
\hline No & Crude Oil & Flow Rate (BOPD) \\
\hline 1 & PT "A" & 3028 \\
2 & PT "B" & 3129 \\
\hline
\end{tabular}


Tabel 4. Hasil Survei Pendahuluan

\begin{tabular}{|c|c|c|c|c|}
\hline No & Lokasi Sampling & $\begin{array}{l}\text { Uji Insitu } \\
\text { SG }\end{array}$ & $\begin{array}{c}\text { Uji } \\
\text { Insitu } \\
\text { BS\&W }\end{array}$ & $\begin{array}{c}\text { Titik } \\
\text { Sampling }\end{array}$ \\
\hline 1 & Platform PT "B" & v & $\sqrt{ }$ & $\begin{array}{c}\text { Separator } \\
\text { V-103 }\end{array}$ \\
\hline 2 & Platform PT “C" & v & $\sqrt{ }$ & $\begin{array}{c}\text { Separator } \\
\text { V-603 }\end{array}$ \\
\hline 3 & FSO “A” & v & $\mathrm{V}$ & $\begin{array}{l}\text { Incoming } \\
\text { FSO "A" }\end{array}$ \\
\hline 4 & FSO “A” & v & $\sqrt{ }$ & $\begin{array}{c}\text { Tangki 3C } \\
\text { FSO "A" }\end{array}$ \\
\hline
\end{tabular}

Sampel yang diterima di laboratorium dilakukan pengujian beberapa sifat fisika-kimia yang berkaitan dengan oil losses.. Sedangkan jenis mata uji dan jumlah pengujian terhadap air formasi dan air laut disajikan pada tabel-tabelselanjutnya dibawah ini

\section{Hasil Uji BS\&W dan SG}

Sebelum dilakukan pencampuran (blending) minyak bumi, terlebih dahulu dihilangkan kandungan airnya (dewatering) sesuai dengan Metode ASTM D-2892. Selanjutnya sampel yang telah di free water dilakukan pengujian $\mathrm{BS} \& \mathrm{~W}$ dan $\mathrm{SG}$ $60 / 60^{\circ} \mathrm{F}$. Hasil uji BS\&W di laboratorium untuk sampelsampel minyak bumi sebelum dan sesudah free water disajikan dalam Tabel 5.

(Manual of Petroleum Measurement Satandards Chapter 10 Sediment and Water, Third Editions, 2008)

Tabel 5. BS\&W (\% vol) Laboratorium: Sampel Minyak

\begin{tabular}{clcc}
\hline & & \multicolumn{2}{c}{ BS\&W (\%vol) } \\
\cline { 3 - 4 } No & Crude Oil & $\begin{array}{c}\text { Before Free } \\
\text { Water }\end{array}$ & $\begin{array}{c}\text { After Free } \\
\text { Water }\end{array}$ \\
\hline 1 & Platform PT "B" & 0,5 & \\
2 & Platform PT "C" & 1,0 & 0 \\
3 & FSO “A" & 50 & \\
4 & FSO "A" & 0 & \\
\hline \multicolumn{3}{c}{ BS\&W : based sediment and water } \\
\hline
\end{tabular}

Hasil uji laboratorium SG $\left(60 / 60{ }^{\circ} \mathrm{F}\right)$ dan salt content untuk sampel-sampel air formasi dan air laut sebelum dan sesudah free water disajikan dalam Tabel 6.

\section{Hasil Simulasi Laboratorium Stabilitas Emulsi}

Tingkat stabilitas emulsi untuk tiap-tiap jenis minyak bumi berbeda-beda tergantung dari karakteristik masing-masing minyak bumi. Salah satu faktor penyebab terjadinya losses pada proses custody transfer minyak bumi kemungkinan diakibatkan karena adanya emulsi yang terhitung sebagai minyak bumi baik yang dikirim maupun yang diterima, pada saat perhitungan standar volume dalam proses pengiriman dan penerimaan produksi minyak bumi, dimana standar volume dihitung berdasarkan volume observasi (pengukuran di lapangan) dikalikan dengan koreksi faktor volume.

$$
V_{s t}=V_{o b s} F K_{v}
$$

dimana $V_{s t}$ adalah volume standar, $V_{o b s}$ adalah volume observasi, dan $F K_{v}$ adalah faktor koreksi volume.

Tabel 6. Specific Gravity $60 / 60{ }^{\circ} \mathrm{F}$ dan Salt Content: Sampel Minyak

\begin{tabular}{|c|c|c|c|c|c|}
\hline \multirow[b]{2}{*}{ No } & \multirow[b]{2}{*}{ Crude Oil } & \multicolumn{2}{|c|}{$\mathrm{SG} 60 / 60^{\circ} \mathrm{F}$} & \multicolumn{2}{|c|}{$\begin{array}{l}\text { Salt Content } \\
\text { (ptb) }\end{array}$} \\
\hline & & $\begin{array}{l}\text { Before } \\
\text { Free } \\
\text { Water }\end{array}$ & $\begin{array}{c}\text { After } \\
\text { Free } \\
\text { Water }\end{array}$ & $\begin{array}{l}\text { Before } \\
\text { Free } \\
\text { Water }\end{array}$ & $\begin{array}{l}\text { After } \\
\text { Free } \\
\text { Water }\end{array}$ \\
\hline 1 & Platform PT "B" & 0,7955 & & 2,4 & \\
\hline 2 & Platform PT "C" & 0,7918 & & 1,6 & \\
\hline 3 & $\begin{array}{l}\text { Incoming FSO } \\
\text { "A" before } \\
\text { treatment T-3C }\end{array}$ & - & 0,7935 & - & 4,39 \\
\hline 4 & $\begin{array}{l}\mathrm{T}-3 \mathrm{C} \text { after } \\
\text { treatment }\end{array}$ & 0,7964 & & 1,9 & \\
\hline
\end{tabular}

Metode pengukuran Salt Content dengan Standar ASTM D3230 dengan Alat Hetrzog Salt Content Analyzer-SC 960 manual.

Tabel 7. Specific Gravity $60 / 60{ }^{\circ} \mathrm{F}$ dan Salt Content: Sampel Formasi dan Air Laut

\begin{tabular}{llrc}
\hline No & \multicolumn{1}{c}{ Sampel } & SG 60/60 ${ }^{\circ} \mathrm{F}$ & Salt as $\mathrm{NaCl}(\mathrm{ptb})$ \\
\hline 1 & AF Poleng & 1,0184 & 10900 \\
2 & AF WMO & 1,0186 & 10620 \\
3 & AF Incoming & 1,0184 & 10760 \\
& Abherka & 1,0248 & 13319 \\
4 & Air Laut & & \\
\hline
\end{tabular}

Nilai $\boldsymbol{F} K_{v}$ (Faktor koreksi volume) diperoleh dari Tabel ASTM 6 berdasarkan nilai temperatur observasi dan SG $60 / 60^{\circ} \mathrm{F} /{ }^{\circ} \mathrm{API}$ dari minyak bumi yang diukur dan dianggap sebagai minyak bumi yang sudah bebas dari air (free water/bebas dari emulsi). Sedangkan nilai SG $60 / 60^{\circ} \mathrm{F} /{ }^{\circ} \mathrm{API}$ yang digunakan dalam menghitung standar volume di lapangan dipakai nilai SG $60 / 60^{\circ} \mathrm{F} /{ }^{\circ} \mathrm{API}$ dari minyak bumi hasil uji laboratorium di lapangan (kemungkinan masih mengandung air dalam bentuk emulsi) sehingga perlu adanya faktor koreksi SG $60 / 60^{\circ} \mathrm{F} /{ }^{\circ} \mathrm{API}$ yang disebabkan adanya emulsi. Hasil uji BS\&W dan SG dari emulsi minyak bumi dengan air formasinya disajikan dalam Tabel 8. Pola pembentukan emulsi sampel minyak PT "B”, PT "C", FSO "A", dan Tangki 3C FSO "A" setelah treatment ditunjukkan pada Gambar 3 sampai Gambar 6. Sedangkan konstanta persamaan emulsi untuk semua sampel ditunjukkan pada Tabel 9.

Tabel parameter emulsi (Tabel 9.) digunakan untuk menghitung losses minyak akibat peristiwa emulsi. Sebagai contoh, misalnya hasil pengukuran BS\&W untuk minyak PT "B" $\left(X_{l}\right)$ adalah $0.5 \%$ maka diperoleh $Y_{l}=0.7966$, selanjutnya dengan mengambil nilai $Y_{2}=Y_{1}$, diperoleh $X_{2}=0.4583 \%$. Koreksi emulsi adalah $X_{1}-X_{2}=0.0417 \%$, sehingga dihasilkan faktor koreksi emulsi PT "C" = $1-0.000417=0.99958$. Dengan cara yang sama dan input BS\&W PT "B" $X_{l}=1.0$, maka diperoleh $Y_{1}=0.7941, X_{2}=0.9583 \%$, dan faktor koreksi emulsi PT "B" = 0.99958, Dari semua data yang ada, volume air yang masuk kedalam FSO sepertinya berasal dari off set 
ketinggian fluid level di dalam separator, kalau pengaturan off set ini tidak tepat dan terlambat dalam adjusting (pengaturan manual) maka air akan masuk terikut mengalir kedalam FSO, hal ini dapat menyebabkan volume air dalam FSO akan bertambah, dan berdasarkan data pengukuran kandungan kadar garam air formasi dan air laut maka dapat dipastikan tidak terjadi intrusi air laut kedalam pipa salur, seperti diperkirakan awal yang menjadi salah satu penyebab bertambahnya air dalam FSO.

Tabel 8. Hasil Uji BS\&W dan SG dari Emulsi Minyak Bumi dengan Air Formasinya

\begin{tabular}{|c|c|c|c|c|c|c|}
\hline \multirow[b]{2}{*}{ Shipper } & \multirow[b]{2}{*}{ Kode } & \multirow{2}{*}{$\begin{array}{c}\% \\
\text { Penam } \\
\text { bahan } \\
\text { Air } \\
\text { Forma } \\
\text { si }\end{array}$} & \multirow[b]{2}{*}{$\begin{array}{c}\text { Penamba } \\
\text { han Air } \\
\text { Formasi } \\
\text { (ml) }\end{array}$} & \multicolumn{3}{|c|}{ Emulsi } \\
\hline & & & & $\begin{array}{l}\text { BSW } \\
(\% \\
\text { vol) }\end{array}$ & $\begin{array}{l}\mathrm{SG} 60 / 60^{\circ} \mathrm{F} \\
\text { Laborato- } \\
\text { rium }\end{array}$ & $\begin{array}{c}\text { SG } \\
60 / 60^{\circ} \mathrm{F} \\
\text { Perhitu- } \\
\text { ngan }\end{array}$ \\
\hline \multirow[t]{6}{*}{ PT "B" } & & 0 & 0 & 0 & 0,7955 & 0,7955 \\
\hline & 1 & 1 & 10 & 0,05 & 0,7959 & 0,7977 \\
\hline & 2 & 2 & 9,5 & 0,6 & 0,7967 & 0,8 \\
\hline & 3 & 3 & 9 & 1,6 & 0,7994 & 0,8022 \\
\hline & 4 & 4 & 8,5 & 1,6 & 0,7994 & 0,8044 \\
\hline & 5 & 5 & 8 & 1,6 & 0,7994 & 0,8066 \\
\hline \multirow[t]{6}{*}{$\begin{array}{l}\text { PT } \\
\text { "C" }\end{array}$} & & 0 & 0 & 0 & 0,7918 & 0,7918 \\
\hline & 1 & 1 & 10 & 0,2 & 0,7921 & 0,7941 \\
\hline & 2 & 2 & 9,5 & 0,6 & 0,7934 & 0,7963 \\
\hline & 3 & 3 & 9 & 1 & 0,7946 & 0,7986 \\
\hline & 4 & 4 & 8,5 & 2 & 0,7966 & 0,8009 \\
\hline & 5 & 5 & 8 & 2 & 0,7966 & 0,8031 \\
\hline \multirow{6}{*}{$\begin{array}{l}\text { Incoming } \\
\text { FSO } \\
\text { "A" }\end{array}$} & & 0 & 0 & 0 & 0,7935 & 0,7935 \\
\hline & 1 & 1 & 10 & 0,4 & 0,7946 & 0,7957 \\
\hline & 2 & 2 & 9,5 & 1,2 & 0,796 & 0,798 \\
\hline & 3 & 3 & 9 & 1,4 & 0,797 & 0,8002 \\
\hline & 4 & 4 & 8,5 & 1,8 & 0,7977 & 0,8025 \\
\hline & 5 & 5 & 8 & 1,8 & 0,7977 & 0,8047 \\
\hline \multirow[t]{6}{*}{$\begin{array}{l}\text { T -3C After } \\
\text { Treatment }\end{array}$} & & 0 & 0 & 0 & 0,7964 & 0,7964 \\
\hline & 1 & 1 & 10 & 0,2 & 0,797 & 0,7986 \\
\hline & 2 & 2 & 9,5 & 1 & 0,7986 & 0,8008 \\
\hline & 3 & 3 & 9 & 1,6 & 0,8002 & 0,8031 \\
\hline & 4 & 4 & 8,5 & 1,6 & 0,8002 & 0,8053 \\
\hline & 5 & 5 & 8 & 1,6 & 0,8002 & 0,8075 \\
\hline
\end{tabular}

Tabel 9. Parameter Koreksi Emulsi

\begin{tabular}{clcccc}
\hline \multirow{2}{*}{ No } & \multirow{2}{*}{ SHIPPER } & \multicolumn{2}{c}{$\mathrm{Y}_{1}=\mathrm{a}_{1} \mathrm{x}_{1}+\mathrm{b}_{1}$} & \multicolumn{2}{c}{$\mathrm{Y}_{2}=\mathrm{a}_{2} \mathrm{x}_{2}+\mathrm{b}_{2}$} \\
\cline { 3 - 6 } & & $\mathrm{a}_{1}$ & $\mathrm{~b}_{1}$ & $\mathrm{a}_{2}$ & $\mathrm{~b}_{2}$ \\
\hline 1 & PT "B" & 0.0022 & 0.7955 & 0.0024 & 0.7955 \\
2 & PT "C" & 0.0023 & 0.7918 & 0.0024 & 0.7918 \\
3 & Incoming FSO & 0.0022 & 0.7935 & 0.0023 & 0.7935 \\
& "A" & & & & \\
4 & FSO “A" T-3C & 0.0022 & 0.7964 & 0.0023 & 0.7964 \\
& after treatment & & & & \\
\hline
\end{tabular}

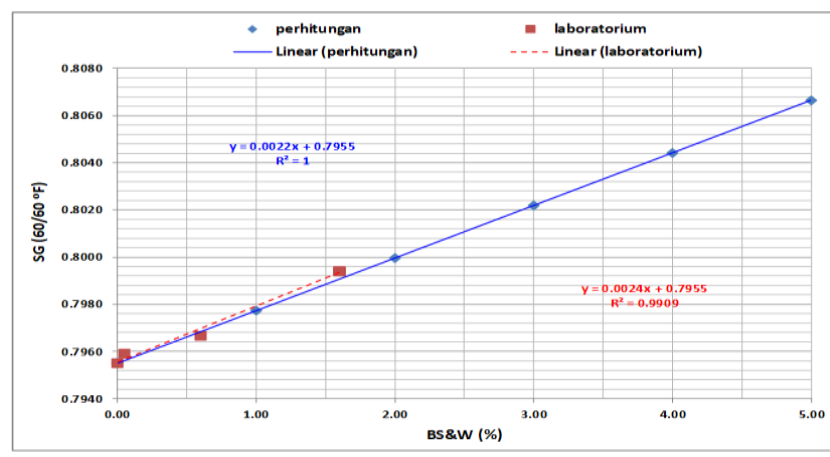

Gambar 3 Pola Pembentukan Emulsi Minyak PT "B"

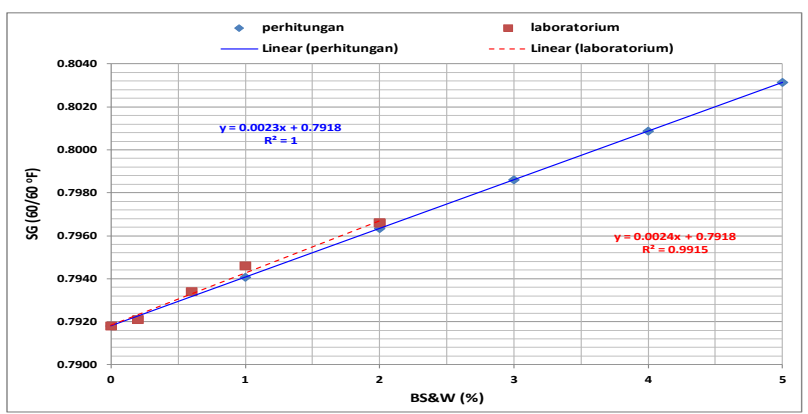

Gambar 4. Pola Pembentukan Emulsi Minyak PT"C”

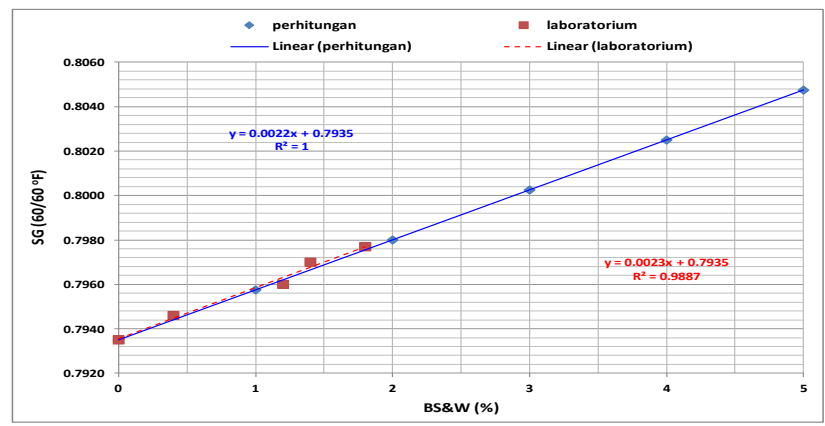

Gambar 5. Pola Pembentukan Emulsi Minyak Incoming FSO "A"

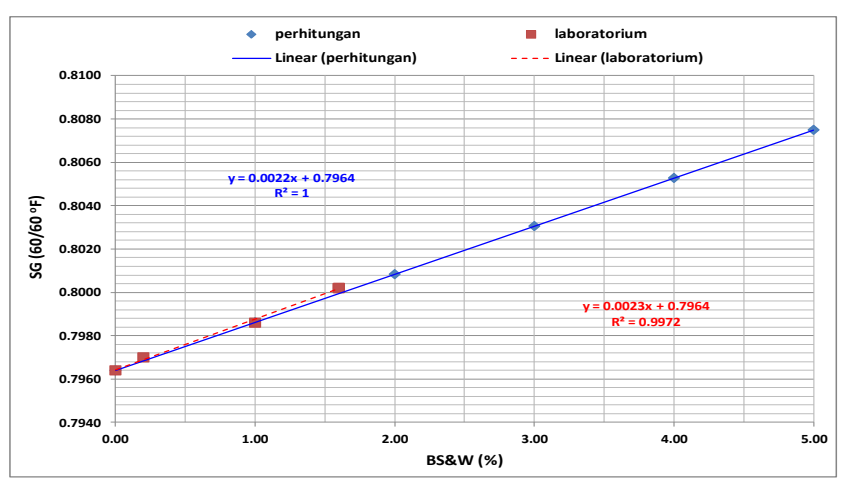

Gambar 6. Pola Pembentukan Emulsi Minyak T-3C After Treatment di FSO "A" 


\section{Kesimpulan}

Berdasarkan pengamatan (uji) laboratorium diperoleh:

1. Sampel minyak PT "B" dan PT "C" memiliki SG yang hampir sama, yaitu $\sim 0.79$ dan $\mathrm{BS} \& \mathrm{~W}$ minyak pada kedua shipper adalah cukup rendah yaitu $0.5-1 \%$.

2. BS\&W sampel pada incoming FSO "A" sangat tinggi, yaitu 50\%; hal ini mengindikasikan adanya off-set pada pengaturan level interface air-minyak di separator sehingga air dapat terikut bersama aliran minyak dari Platform ke FSO "A"

3. Berdasarkan hasil analisa air formasi dari produksi kedua shipper dan analisa air laut tidak terjadi intrusi air laut (sepert asumsi awal) ke dalam sistem penyaluran minyak.

\section{Rekomendasi}

1. Perlu dilakukan field trial pengaturan set point level interface separator untuk mengetahui seberapa besar pengaruhnya terhadap volume air yang ikut terkirim bersama minyak menuju FSO "A"

2. Pengubahan/pengaturan set point level separator agar dapat di adjust di control room sehingga mempermudah dan mempercepat operator jika ingin mengubah set point level.

3. Menambahkan automatic sampler untuk memperoleh sampel minyak yang representative. Automatic sampler yang digunakan mengacu pada API 8.2 dengan system flow base.

\section{Daftar Pustaka}

Intertanko, 1996. Oil Cargo Losses and Problems with Measurement 2nd Edition. International Association of Independent Tanker Owners, London

Jones, P., 1985. Oil loss, measurement and control. A paper presented to the Chinese Petroleum Society, China, July: $2-29$

Manual of Petroleum Measurement Satandards Chapter 10, Sediment and Water, Third Editions, 2008

API MPMS Chapter 10.2 (1'st Edition 1981 - Reaffirmed 2005)

Analisa BS \& W By CentrifugeASTM - D - 6/API-2542 